\title{
Analysis of difficulties occurring during the early auditory screening in children
}

\author{
Authors' Contribution: \\ A-Study Design \\ B-Data Collection \\ C-Statistical Analysis \\ D-Data Interpretation \\ E-Manuscript Preparation \\ F-Literature Search \\ G-Funds Collection \\ Sebastian Kocoń ${ }^{\mathrm{BDDEC}}$, Maciej Wiatr ${ }^{\mathrm{DE}}$, Paweł Strę $\mathrm{k}^{\mathrm{CEF}}$, Agnieszka Wiatr ${ }^{\mathrm{CEF}}$, \\ Aleksandra Grudzień-Ziarno ${ }^{\mathrm{BF}}$, Patryk Hartwich ${ }^{\mathrm{CE}}$ \\ Jagiellonian University, Cracow, Poland
}

Article history: Received:13.04.2016 Accepted:04.05.2016 Published:10.07.2016

ABSTRACT:

Introduction: It is assumed that the critical period for diagnosis of hearing disorders is the baby's first three months of life and that appropriate course and implementation of treatment and/or rehabilitation should begin before a child is six months old.

However various kinds of problems may occur during auditory screening of a child may exceed this interval. This problem is particularly pronounced among children with development and health problems and leads to unreliable and varied results.

Aim: The aim of this study was an analysis of prevalence of difficulties occurring during the first year of auditory screening among groups of children with congenital hearing impairment.

Material and methods: Patients were examined in The Universal Newborn Hearing Screening Program in the years 2012-2013 in Level III NICUs in Krakow. Results from 250 cases were analyzed retrospectively. Medical exam results of patients with high risk of hearing loss were also included in our analysis. The groups of children included in our study were: children with Down Syndrome, children with nervous system disorders, children with cleft palate or both cleft palate and lip and children with congenital CMV.

Results: In the group of children with cleft palate or both cleft palate and lip the most frequent cause of not conducting objective audiometric tests was bad health condition of a child which precluded his arrival for administering the tests. The most common cause of difficulties in performing hearing tests was the emotional state of children from groups with Down Syndrome. In the group of children with congenital CMV the most common cause of difficulties was a lack of availability of their parents.

Conclusions: 1. We encountered the greatest diagnostic difficulties during the child's first year of life in chosen highrisk groups of children with congenital hearing loss in children with cleft palate or both cleft palate and lip.

2. The highest prevalence of not finished tests was in III and IV interval for all chosen high-risk groups with congenital hearing loss.

KEYWORDS: $\quad$ hearing disorders, audiology, screening newborns hearing tests

\section{INTRODUCTION:}

Early detection of hearing impairment in children has become a standard nowadays. Diagnostic procedure involves: screening tests in the second day of life and in the event of diagnosing a hearing problem (positive test) a repeated test before discharge from the neonatal unit $[1,2]$.

It was accepted that transient-evoked acoustic otoemission (TEOAE) is the best method of neonatal screening for hear- ing impairment in everyday neonatal practice, followed by ABR (auditory brainstem response) $[2,3,4]$.

Children with positive result of the screening test (impaired hearing) and children at particular risk of congenital hearing disorders are referred to secondary and tertiary referral hospitals for further diagnostics and follow-up. Children at risk of congenital hearing impairment are referred to such centers even in the event of negative result of screening tests (i.e. proper hearing) $[2,5,6,7]$. 
According to the current standards, auditory screening in neonates should be conducted in line with the following scheme:

\section{Neonatal screening tests}

Examining children on the second day after birth and, in case of diagnosed hearing impairment or presence of risk factors for hearing impairment, child's parents/caregivers are referred to centers specializing in such problems.

\section{Further diagnostics at secondary and tertiary referral centers for neonatal screening tests}

It is agreed upon that the first three months of life is the optimal period for conducting the diagnostics of hearing impairment, while proper therapy and implementation of treatment and/or physical therapy should be commenced before the end of the sixth month.

In practice, there are various kinds of difficulties occurring at the diagnostic stage in children that extend the time to diagnosis and implementation of proper management, e.g. implantation of a hearing aid. The problem is particularly apparent in patients with additional health issues, such as genetic disorders, problems arising from perinatal complications, viral infections (e.g. CMV).

This work presents an analysis of factors that might delay implementation of screening tests.

\section{AIM:}

The goal of this work is to analyze the difficulties occurring during the first year of audiological diagnostics and to indicate their causes in selected groups of children with congenital hearing impairment.

\section{MATERIAL AND METHODS:}

A total of 2464 patients were examined at a tertiary referral center participating in PPPBSN - Specialist Outpatient Diagnosis and Rehabilitation Center for Hearing Impaired Children and Youth of Polish Association of the Deaf in Cracow during years 2012-2013. Retrospective analysis was conducted on 250 children. Test results of 138 girls and 112 boys were examined. Study group consisted of children between the first and third month of life. The analysis included test results of patients with risk factors for hearing impairment.
For the purpose of the study patients were divided into four groups, where difficulties delaying final diagnosis and implementation of proper treatment are observed in clinical practice $[22,29,35,42,47,85,137]$ :

- Group I - children with Down syndrome (62 children).

- Group II - children with other disorders or central nervous system damage (66 children) (hypoxicischemic syndrome, meningitis, abnormal muscle tone, hydrocephalus, cerebral palsy, epilepsy, other neurodegenerative diseases) $[8,9,10]$

- Group III - children with cleft palate or cleft lip and palate (54 children)

- Group IV - children with congenital CMV infection (68 children)

Result of TEOAE screening test performed at the neonatal unit was considered the baseline.

Subsequently, we analyzed the results obtained over the first year of child's life. Three tests were taken into consideration: impedance audiometry, TEOAE and ABR using click stimulus.

The first year of child's life was divided into four diagnostic periods:

- 1-3 months of life

- 4-6 months of life

- 7-9 months of life

- 10-12 months of life

Statistical methods were used for data analysis. Results were considered statistically significant for $\mathrm{p} \leq 0.05$.

Due to the character of results of diagnostic tests we used descriptive statistics in data analysis - results were presented as percentage values.

\section{RESULTS:}

Test results of 250 children, including 138 girls and 112 boys, diagnosed between 2012 and 2013 were subjected to retrospective analysis. Patient age at the time of inclusion into the study ranged from 0 to 3 months.

Throughout all diagnostic periods, the greatest proportion of children who experienced problems with implementation of all three tests (impedance audiometry, TEOAE, ABR) consisted of patients with cleft palate or cleft lip and palate, as well as children with Down syndrome. Particular attention should be paid to the third diagnostic period, where the proportion 
of children with cleft palate or cleft lip and palate reached as much as $50.2 \%$. Stable rates of failure to perform all diagnostic tests throughout all diagnostic periods were observed among groups of children with other disorders or nervous system damage. It fluctuated around $15 \%$ in children with other comorbidities or central nervous system damage and around $10 \%$ among children with congenital CMV infection.

In the group of children with Down syndrome (Figure 1) it was observed that patient's condition (illness, surgery) was an important factor preventing completion of the test. High rates of failure to perform diagnostic tests due to such reasons was maintained over all of the examined diagnostic periods and amounted to $7.5 \%$ in diagnostic period I, 9.7\% in diagnostic period III, $10.8 \%$ in diagnostic period IV, and as much as $14 \%$ in diagnostic period II.

Inability to perform the test due to child's emotional state was most often identified in diagnostic period I $-10.8 \%$ with a tendency to decrease over the subsequent periods $-8.6 \%$ in diagnostic period II and 7\% in diagnostic period IV. Parental unavailability was the least common cause of failure to perform the test and did not exceed $4.8 \%$ in all of the analyzed diagnostic periods.

Among children with other disorders or central nervous system damage we observed that child's emotional condition was an important factor preventing examination. There was a decreasing tendency in the subsequent diagnostic periods. In the diagnostic period I this proportion reached 7.3\%, in the second period $-6.8 \%$, in the third $-6.3 \%$, and in the diagnostic period IV it was reduced down to $5.2 \%$. In this group, percentage of causes defined as child's condition that prevented reporting to the examination (illness, surgery) was $4.7 \%$ for diagnostic period I, increased to $5.7 \%$ in the second diagnostic period, and subsequently became reduced to $4.2 \%$ in the third period and $2.6 \%$ in diagnostic period IV.

Rate of failure to perform the examination due to lack of parental availability was characterized by an increasing tendency in this group and amounted to $0.6 \%$ for diagnostic period I, 2.6\% for the second diagnostic period, followed by $5.2 \%$ and $6.2 \%$ for diagnostic periods III and IV, respectively (Figure 2).

Among children with cleft palate or cleft lip and palate the most frequent cause of failure to perform the test was child's general condition that prevented reporting to the examination (illness, surgery). It most often concerned the diagnostic period III (28.4\%) and diagnostic period IV (16.7\%). Proportion of tests that were not performed due to child's emotional

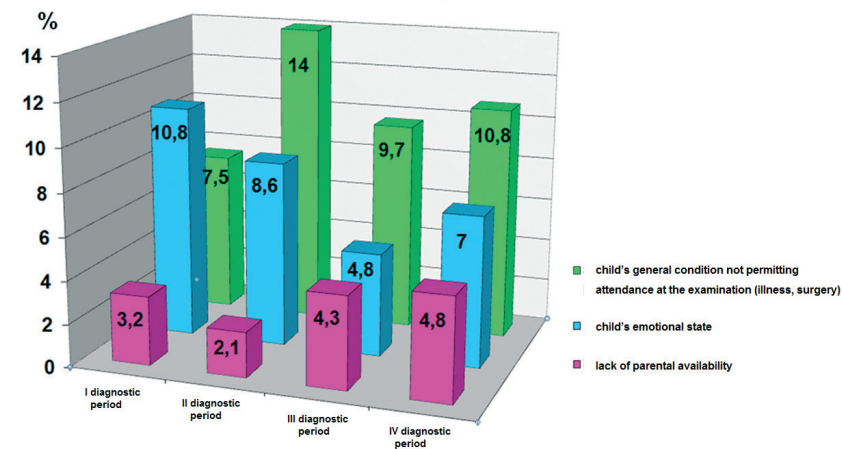

Fig. 1. Causes of failure to perform the examination among patients with Down syndrome. I/II/III//V okres diagnostyczny - diagnostic period I/II/III/IV

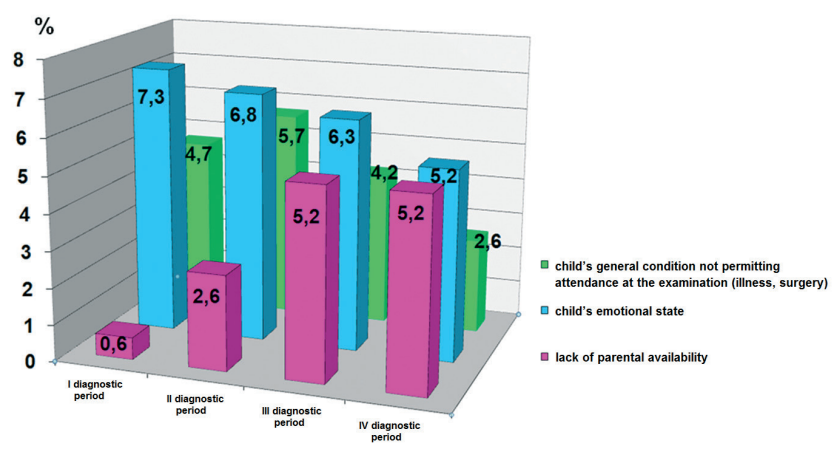

Fig. 2. Causes of failure to perform the examination-children with other disorders or nervous system damage depending on the diagnostic period

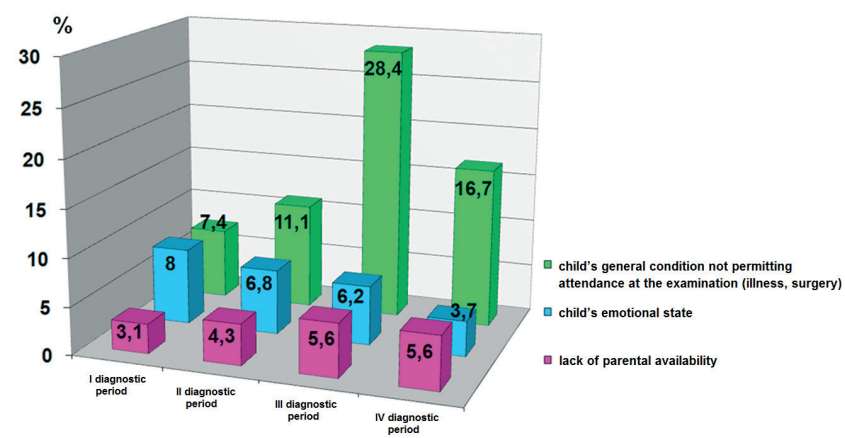

Fig. 3. Causes of failure to perform the examination among children with cleft palate or cleft lip and palate depending on the diagnostic period

state decreased with time over the examined diagnostic periods. In diagnostic period I it amounted to $8 \%$, in diagnostic periods II and III it reached $6.8 \%$ and $6.2 \%$, respectively, and $3.7 \%$ in diagnostic period IV.

Rate of failure to complete the examination due to lack of parental availability amounted to $3.1 \%$ in diagnostic period I 
and exhibited a slightly growing tendency, reaching 5.6\% in diagnostic periods III and IV (Figure 3).

Among children with congenital CMV infection we observed that later diagnostic period was associated with increased rate of failure to perform the examination due to lack of parental availability - from $2.5 \%$ in the first diagnostic period to $6.9 \%$ in the fourth. It was also noted that inability to perform the examination due to child's emotional state was reduced in subsequent diagnostic periods - for diagnostic period I it amounted to $3.9 \%$, for periods II and II $-3 \%$, and $1.5 \%$ for diagnostic period IV.

However, patient's general condition that prevented reporting to the examination (illness, surgery) was most often the cause in the diagnostic period III (3.9\%). For the diagnostic period IV the proportion amounted to $2.9 \%$ and $2 \%$ for periods I and III (Figure 4).

Figure 5 presents causes of failure to perform the test among children from particular groups. Child's poor general condition (e.g. surgery) was the most common cause of missing the test in children with cleft palate or cleft lip and palate $15.9 \%$. In the group of children with Down syndrome this proportion reached $10.4 \%$. In the remaining groups proportions were, respectively, $4.3 \%$ for children with other disorders or central nervous system damage, and $2.7 \%$ for children with congenital CMV infection.

Failure to perform the test due to child's emotional state was most common among children with Down syndrome $-7.8 \%$. Among children with other disorders or central nervous system damage the proportion reached $6.4 \%$, in children with cleft palate or cleft lip and palate $-6.2 \%$, and $2.9 \%$ in children with congenital CMV infection.

$3,4 \%$. The greatest rate of failures to report to the test due to lack of parental/caregiver's availability was found in the group of children with cleft palate or cleft lip and palate $4.6 \%$. In children with congenital CMV the proportion was $4.2 \%$, in the group of children with Down syndrome $-3.6 \%$, and among children with other disorders or central nervous system damage it reached $3.4 \%$.

\section{DISCUSSION:}

According to the data provided by WOSP [charity organization], over 4.5 million children amounting to almost $100 \%$ of all newborn children were examined since 2002, when the Universal Newborn Hearing Screening Program was first im-

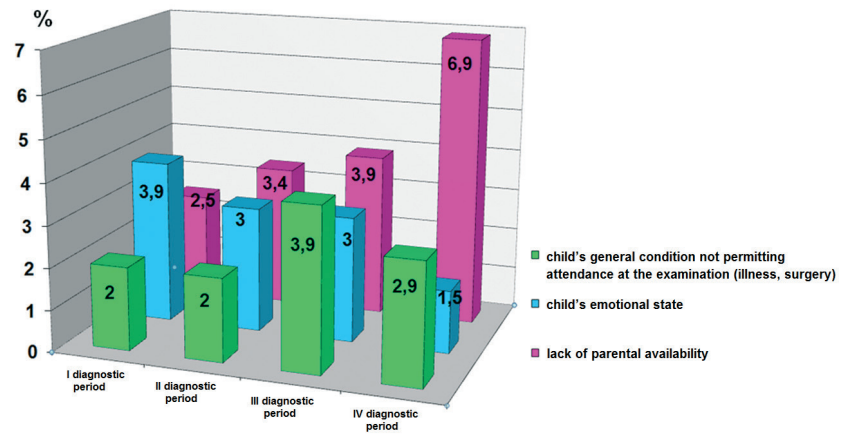

Fig. 4. Causes of failure to perform the examination among children with congenital CMV infection depending on the diagnostic period

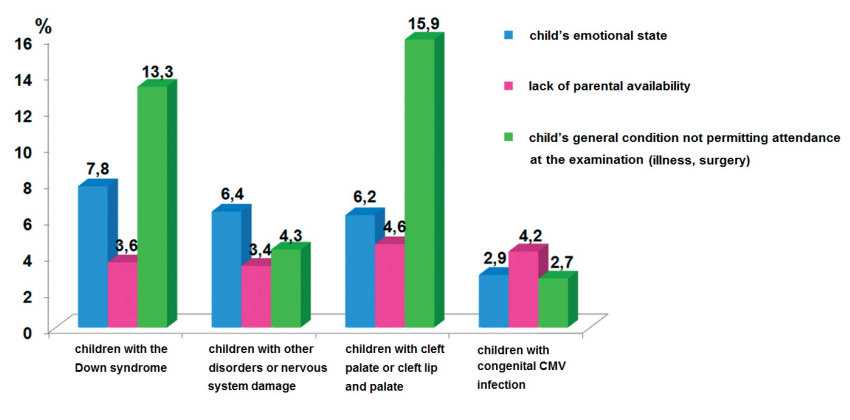

Fig. 5. Causes of failure to perform the examination among children from selected risk groups for congenital hearing impairment.

plemented. It is believed that hearing problems are some of the most common abnormalities occurring in the neonatal period $[6,11,12]$. Risk factors for hearing loss are identified in only about a half of all children with congenital hearing impairment $[13,14]$.

Congenital hearing impairment in a child leads to impedance of speech development, which subsequently influences psychological, intellectual as well as social development [15]. Even with hearing loss of $>30 \mathrm{~dB}$ a child may present with articulation problems and hearing impairment $\geq 40 \mathrm{~dB}$ requires application of hearing aids [16].

Since the very beginning of existence of PPPBSN the procedures and guidelines for the diagnostics are being constantly improved. The first three months of child's life is the optimal period for conducting diagnostics of hearing impairment and therapeutic management, including physiotherapy, should be commenced before the end of sixth month of life [17]. However, it should be emphasized that in the recent years, with spreading of objective methods, age of diagnosis decreased to 1 month. 
The child needs to stay calm during otoacoustic emissions. It does not have to be asleep, but for proper completion of the study the child needs to be calm enough to enable proper placement of the measuring probe in the external auditory canal and there should not be any interference due to screaming or excessive body movements. If the above-mentioned conditions are not met, the instrument reports a problem with recording a measurable signal. For that reason, the personnel performing the test together with child's parents try to calm it down or, optimally, put it to sleep. If it is not possible to reach the level of calmness need for proper completion of the study, child's parents/caregivers sign up for the examination at another time.

ABR examination in children, particularly those analyzed in this publication i.e. aged up to 1 year, is performed during sleep. Sleeping is required to obtain measurable signal. If the little patient does not fall asleep, the interference signals generated by the child (crying, excessive movement activity) make the acquired results unreliable and the test needs to be repeated. In the majority of centers the study is performed during physiological sleep following proper patient preparation. When signing up for ABR test child's parents/caregivers receive information on the nature of the study and how it is carried out.

Obstacles that might significantly influence the course of testing or prolong the time to obtaining final, reliable results and establishing final diagnosis include the following:

- frequent infections,

- occurrence of the first signs of infection on the day of the test (runny nose, fever) or recent and incompletely cured infections causing unreliable test results,

- narrow auditory canals and a tendency toward producing large amounts of wax,

- gastrointestinal disorders (spitting food, gastroesophageal reflux),

- emotional arousal in a child or sleeping problems that make it impossible to conduct the study (child's sleep is a requirement for performing $\mathrm{ABR}$ ),

- congenital abnormalities,

- failure to report to the test.

Summarizing all of the discussed difficulties associated with failure to perform all audiological examinations among children belonging to the selected groups it may be concluded that the greatest proportion of children with problems completing all three tests (impedance audiometry, TEOAE, ABR) was identified in the cleft palate/cleft lip and palate group. Particular attention should be paid to the diagnostic period III, where the rate of failure reached
$40.2 \%$ in this group. Possible explanation for the highest rate of failure to perform audiological studies in children with cleft palate or cleft lip and palate may be such that the clinical symptoms of the malformation dominating during the analyzed period in this group hindered completion of the tests.

Difficulties associated with congenital malformation, i.e. problems taking in food, "spitting", greater amount of secretions, frequent infections, etc. make audiological diagnostics in the first year of life in this group of patients difficult with regard to assessment of the quality and level of hearing.

Among children with Down syndrome the proportion of difficulties related to conducting tests was also significant (about 20\%). The causes were largely associated with difficulties characteristic for this genetic condition (narrow auditory canals, frequent infections, emotional lability). It is important to emphasize that in this group of children this rate did not change significantly over all of the examined diagnostic periods.

In the group of children with other disorders or central nervous system damage we observed a stable proportion of difficulties associated with failure to conduct the study throughout all of the diagnostic periods. It amounted to about $15 \%$. This constant tendency may be explained by the observation that from a medical point of view no great changes in the level or quality of hearing should be expected in this group of children.

In children with congenital CMV infection we also observed a relatively stable proportion of failures performing auditory tests (about 10\%), but with a tendency for growth $-8.4 \%$ in diagnostic period I, $10.8 \%$ in diagnostic period II, and $11.3 \%$ in diagnostic period IV. Especially in this group of children with congenital CMV infection medical personnel conducting the tests particularly frequently encounters questions regarding validity of further auditory testing. Seeing that the child is reacting to sounds, parents often underestimate the problem of possible hearing deterioration and, as a result, fail to report to follow-up laryngological/ audiological visits.

After analyzing the gathered data we concluded that difficulties influencing audiological diagnostics in children ensue from the following factors:

- child's medical condition that prevents reporting to the examination (illness, surgery),

- child's emotional state,

- lack of parental/caregiver's availability. 
During consecutive follow-up examinations we noted increasing rate of appointment absence, particularly among patients with congenital CMV infection.

One of possible explanations for this phenomenon is such that parents/caregivers are more disciplined in the early diagnostic period, but begin to underrate the problem as the diagnostics prolong.

Despite a large number of patients, in case of child's absence to the control tests medical personnel should set another appointment for examination/consultation as early as possible. In order to avoid prolonged waiting times, a special action plan and a schedule is created, where additional hours are reserved for children requiring urgent diagnostics as well as for those who have not undergone elective examination for various reasons.

Conducted analysis demonstrated that, as predicted, the greatest diagnostic difficulties occurred in the group of children with cleft palate/cleft lip and palate, particularly with regard to the third and fourth diagnostic period. In the group of children with cleft palate or cleft lip and palate reconstructive surgery for repair of the malformation was an important factor influencing determination of child's hearing level during the analyzed period.

In the group of children with Down syndrome we also identified significant difficulties in conducting audiological studies over the selected diagnostic periods. In case of ABR study, the problem of failure to perform the examination concerned as much as $1 / 3$ of children.

Among children with other disorders or neurological damage the proportion of failures during the diagnostic tests is estimated at $25 \%$. Therefore, following analysis of the results of audiological tests and hearing threshold stability throughout the selected diagnostic periods, we concluded that it is reasonable to base further management on the results of tests obtained during the first two diagnostic periods. Follow-up tests usually corroborated previous results. It is worth noting, that due to the character of neurological abnormalities occurring in this group of patients that might affect child's hearing and development, individual approach should be undertaken in each case.

We did not observe a significant proportion of patients with hearing impairment among children with congenital CMV infection. Results of audiological tests indicated the lowest rate of hearing impairment of all analyzed groups. However, it should be emphasized that the time period con- sidered in our study is shorter than the period, in which the influence of CMV on hearing may be observed. Thus, children from this group constituted the greatest proportion of patients referred for further audiological follow-up. This group was characterized by the lowest rate of occurrence of factors hindering audiological diagnostics.

Conducted analysis of causes of failure to perform scheduled control examinations demonstrated the following reasons for absence: child's health, emotional state and lack of parental/caregiver's availability. It was also observed that child's general condition was the most common reason for not performing the examination in the group of patients with Down syndrome and the cleft palate/cleft lip and palate group. The greatest proportion of children who failed to complete the testing due to emotional state was observed in the Down syndrome group. On the other hand, lack of parental availability was the main reason for not performing the test among children with congenital CMV infection.

\section{CONCLUSIONS:}

- The greatest diagnostic difficulties in the first year of life were observed among children with cleft palate or cleft lip and palate.

- The greatest rates of failure to perform the test were observed in the third and fourth diagnostic period for all identified risk groups for hearing impairment.

- In the group of children with cleft palate or cleft lip and palate as well as in the Down syndrome group child's general condition that did not permit reporting to the examination was the most frequent cause of not performing objective audiological tests.

- Child's emotional state preventing completion of objective diagnostic tests was the most frequent cause of diagnostic difficulties in the group of Down syndrome patients.

- In the group of children with congenital CMV infection parental unavailability was the most frequent cause of failure to perform audiological studies.

- When it comes to children from selected groups at particular risk of congenital hearing impairment it is sometimes necessary to apply extraordinary measures for organizing diagnostic examinations in order to establish final diagnosis as quickly as possible. 


\section{REFERENCES}

1. Kochanek K.: Powszechne badania przesiewowe słuchu u noworodków. Magazyn Otolaryngologiczny. 6, 2003 , II (2), 50-51.

2. Kochanek K.: Otolaryngologia dziecięca, red. Gryczyńska D., Łódź 2007, 81-87.

3. Kochanek K.: Audiologia Kliniczna Mediton, red. Śliwińska-Kowalska M., Łódź 2005, 391-396.

4. Spivak L., Sokol H.: Beyond newborn screening: early diagnosis and management of hearing loss in infants. Advances in Neonatal Care, 2005, 5 (2), 104-112.

5. Beswick R., Driscoll C., Kei J.: Monitoring for postnatal hearing loss using risk factors: a systematic literature review. Ear Hear. 2012 , 33 (6), 745-756.

6. Dobrzańska A., Gołkowska M., Janowska J., Czech-Kowalska J., Pleskoczyńska A.: Kliniczne zastosowanie otoemisji akustycznych we wczesnej diagnostyce uszkodzenia słuchu u noworodków i niemowląt. Postępy Neonatologii, 2003, 1 (1), 71-79.

7. Wróbel M.: Czynniki ryzyka w analizie I poziomu referencyjności PPPBSuN, Podsumowanie działalności II i III poziomu referencyjności. Uszko - Biuletyn Programu Powszechnych Przesiewowych Badań Słuchu u Noworodków, 2011, 8-17.

8. Perrot X., Ryvlin P., Isnard J. et al.: Evidence for corticofugal modulation of peripheral auditory activity in humans. Cereb Cortex, 2006, 16 (7), 941-948.

9. Elkabariti R.H., Khalil L.H., Husein R., Talaat H.S.: Speech evoked auditory brainstem response findings in children with epilepsy. Int. J. Pediatr. Otorhinolaryngol., 2014, 78 (8), 1277-1280.

10. Soliman S., Mostafa M., Kamal N. et al.: Auditory evoked potentials in epileptic patients. Ear Hear, 1993, 14 (4), $235-241$.

11. American Academy of Pediatrics: Newborn and infant hearing loss: detection and intervention. Pediatrics, 1999,103 (2), $527-531$.

12. Schieve L.A., Boulet S.L., Boyle C., Rasmussen S.A., Schendel D.: Health of children 3 to 17 years of age with Down syndrome in $1997-2005$ National Health Interview Survey. Pediatrics, 2009, 123, 253-260.

13. DeConde Johnson C.: Hearing and immittance screening [w]: Handbook of Clinical Audiology, Fifth edition. Katz J., Lippincott Williams and Wilkins, Philadelphia 2002, 24, 481-493.

14. Fowler K.B., Dahle A.J., Boppana S.B.: Newborn hearing screening: Will children with hearing loss caused by congenital cytomegalovirus infection be missed? J. Pediatr., 1999, 135, 60-64.

15. Pruszewicz A., Obrębowski A.: Wpływ zaburzeń słuchu na rozwój dziecka. Audiologia Kliniczna Zarys, red. Pruszewicz A., UM, Poznań 2010, 598-599.

16. Kurkowski Z.M.: Proces porozumiewania się w interakcjach: matka - niesłyszące dziecko, Audiofonologia, 1996, t. VIII, $147-166$.

17. Cutler J., Lenzi G., Berrettini S. et al.: How to motivate newborn hearing screening in the absence of a national programme: a collaboration between parents and professionals. J. Maternal-Fetal \& Neonatal Medicine, 2012, 25(4): 114-115.

Word count: 3500 Tables:- Figures: 5 References: 17

Access the article online: DOI: 10.5604/00306657.1202780 Full-text PDF: www.otolaryngologypl.com/fulltxt.php?ICID=1202780

Corresponding author: Maciej Wiatr; Jagiellonian University Otolaryngology Department, Crakow, Poland; e-mail: mwiatr@mp.pl

Copyright $\odot 2016$ Polish Society of Otorhinolaryngologists Head and Neck Surgeons. Published by Index Copernicus Sp. z o.o. All rights reserved.

Competing interests: The authors declare that they have no competing interests.

Cite this article as: Kocoń S., Wiatr M., Stręk P., Wiatr A., Grudzień-ZiarnoA., Hartwich P.: Analysis of difficulties occurring during the early auditory screening in children; Otolaryngol Pol 2016; 70 (4): 47-54 